\title{
Advanced risk-based event attribution for heavy regional
}

\section{rainfall events}

\author{
Yukiko Imada $\mathbb{D}^{1 凶}$, Hiroaki Kawase ${ }^{1}$, Masahiro Watanabe $\mathbb{D}^{2}$, Miki Arai ${ }^{3}$, Hideo Shiogama $\mathbb{D}^{4}$ and Izuru Takayabu ${ }^{1}$
}

Risk-based event attribution (EA) science involves probabilistically estimating alterations of the likelihoods of particular weather events, such as heat waves and heavy rainfall, owing to global warming, and has been considered as an effective approach with regard to climate change adaptation. However, risk-based EA for heavy rain events remains challenging because, unlike extreme temperature events, which often have a scale of thousands of kilometres, heavy rainfall occurrences depend on mesoscale rainfall systems and regional geographies that cannot be resolved using general circulation models (GCMs) that are currently employed for risk-based EA. Herein, we use GCM large-ensemble simulations and high-resolution downscaled products with a 20-km nonhydrostatic regional climate model (RCM), whose boundary conditions are obtained from all available GCM ensemble simulations, to show that anthropogenic warming increased the risk of two record-breaking regional heavy rainfall events in 2017 and 2018 over western Japan. The events are examined from the perspective of rainfall statistics simulated by the RCM and from the perspective of background large-scale circulation fields simulated by the GCM. In the 2017 case, precipitous terrain and a static pressure pattern in the synoptic field helped reduce uncertainty in the dynamical components, whereas in the 2018 case, a static pressure pattern in the synoptic field provided favourable conditions for event occurrence through a moisture increase under warmer climate. These findings show that successful risk-based EA for regional extreme rainfall relies on the degree to which uncertainty induced by the dynamic components is reduced by background conditioning.

npj Climate and Atmospheric Science (2020)3:37; https://doi.org/10.1038/s41612-020-00141-y

\section{INTRODUCTION}

It is widely acknowledged that global warming significantly affects the features of extreme events ${ }^{1}$. Several studies have focused on identifying changes in the occurrence of extreme events that could be linked to anthropogenic activities or natural variability. However, quantifying changes in the likelihood of rare events is not straightforward. EA based on historical/counterfactual-nonwarming simulations by state-of-the-art climate models is a possible solution for quantitatively estimating the impact of human activities on a specific event ${ }^{2}$. With regard to $E A$, two questions have been raised: (1) how has anthropogenic climate change altered the probability of occurrence of individual extreme events (known as the 'risk-based' approach; hereafter risk-based $E A)^{3,4}$ and (2) how has the severity (i.e. magnitude or intensity) of extreme events changed due to climate change (known as the 'storyline' approach; hereafter storyline EA $)^{5}$. For the risk-based approach, large-ensemble simulations targeted at one single event are required to represent the probability density function (PDF) of the event occurrence. However, for the storyline approach, model boundary conditions are strictly constrained by realistic background atmospheric conditions to ensure the occurrence of the event of interest. Through these approaches, a reasonable degree of consensus can be obtained on the attribution of temperature extremes to anthropogenic climate change, e.g. refs. ${ }^{6,7}$. However, there is less agreement in risk-based EA regarding extreme precipitation $^{8-15}$. Globally, the moisture increase caused by warmer atmospheric temperature agrees with the Clausius-Clapeyron relation of $\sim 7 \%$ saturated vapour per Kelvin ${ }^{1}$; however, local precipitation changes are influenced by moisture availability, atmospheric circulation and vertical stability ${ }^{16,17}$. Furthermore, disastrous extreme precipitation is often strongly linked to mesoscale rainfall systems and specific geography ${ }^{18}$. Precipitation takes different forms of atmospheric circulation in each location. The conventional global climate models used for risk-based EA typically cannot capture these features of extreme precipitation events $^{9}$; therefore, a high-resolution regional model is required. Several previous risk-based EA studies incorporated regional climate models ${ }^{11,12,14,15}$, although their model evaluations were primarily based on heavy rainfall statistics, and representation of background synoptic circulation patterns and mesoscale rainfall systems were not fully considered.

Thus far, high-resolution RCMs have been mainly used in storyline EA. Kawase et al. ${ }^{19}$ simulated the heavy rain event of July 2018 in Japan using an RCM with realistic initial and boundary conditions based on the reanalysis data and found that the record-breaking precipitation could be attributed to recent rapid warming through comparison between hindcast and detrended experiments. This technique is similar to the 'pseudo-global warming' approach and has been extensively used for storyline EA of tropical cyclones (TCs). Previous studies conducted a storyline EA aimed at TC-induced extreme events based on RCM and variable-resolution GCM simulations and showed significant impacts of global warming on rainfall amounts, wind speed, storm size and storm surge height ${ }^{20-24}$. However, storyline attribution cannot make a statement about the changes in cyclogenesis rates or the probability because it is conditional on the event's underlying existence ${ }^{20,24}$.

Thus, complete assessments of the effect of anthropogenic climate change on extreme rainfall events must be based on a combination of the storyline EA and risk-based EA. Wang et al. ${ }^{25}$

\footnotetext{
${ }^{1}$ Meteorological Research Institute, Japan Meteorological Agency, 1-1 Nagamine, Tsukuba, Ibaraki 305-0052, Japan. ${ }^{2}$ Atmosphere and Ocean Research Institute, the University of Tokyo, 5-1-5 Kashiwanoha, Kashiwa, Chiba 277-8568, Japan. ${ }^{3}$ Japan Agency for Marine-Earth Science and Technology, 3173-25 Showa-machi, Kanazawa-ku, Yokohama, Kanagawa 236-0001, Japan. ${ }^{4}$ National Institute for Environmental Studies, 16-2 Onogawa, Tsukuba, Ibaraki 305-8506, Japan. ${ }^{凶}$ email: yimada@mri-jma.go.jp
} 


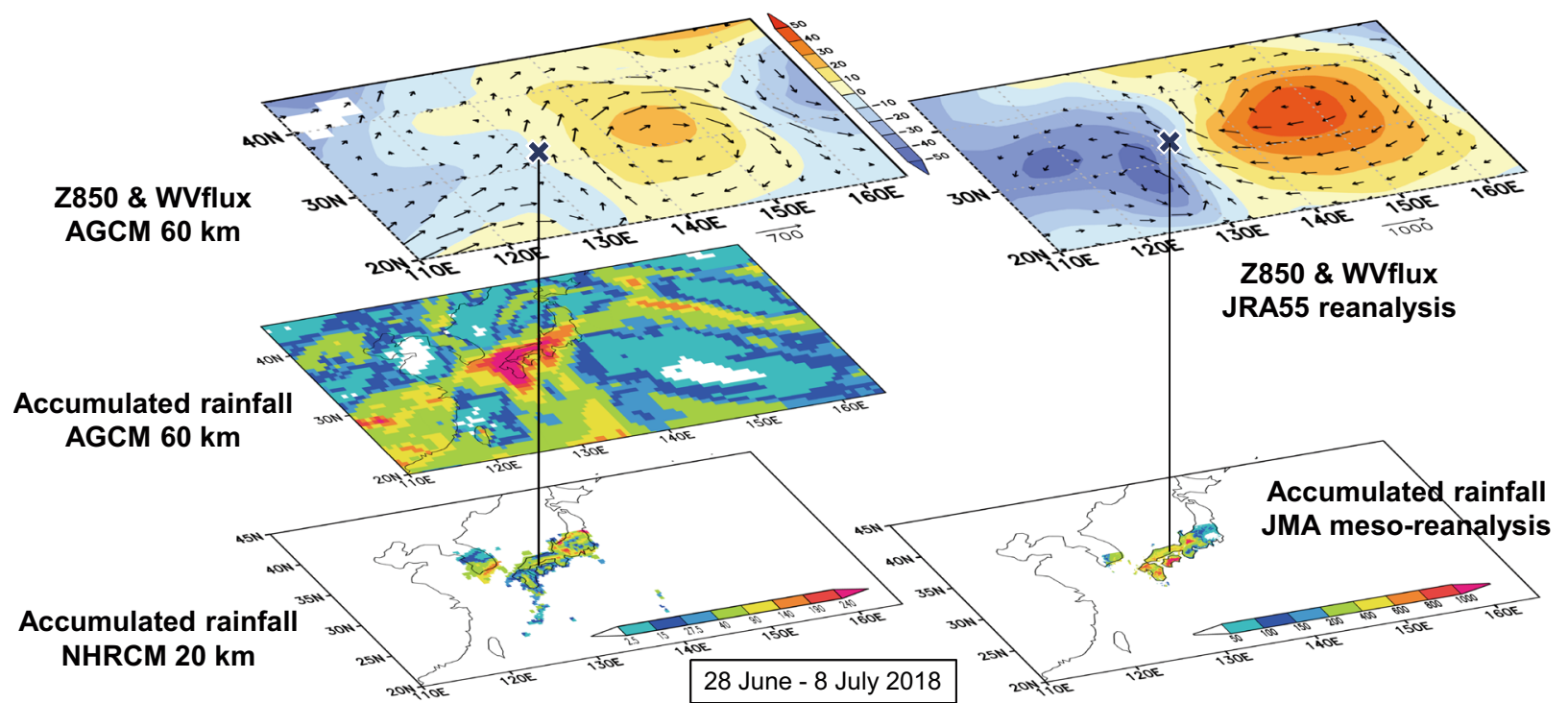

Fig. 1 Schematic demonstrating advantages of using large-ensemble pairs of AGCM and NHRCM. The upper two panels show anomalies of $Z 850[\mathrm{~m}]$ and column-integrated water vapour fluxes $\left[\mathrm{kg} \mathrm{m}^{-1} \mathrm{~s}^{-1}\right]$ (shading and vectors in upper panels) averaged from $28 \mathrm{June}$ to $8 \mathrm{July,}$ 2018 over East Asia, where the right was obtained from the JRA55 reanalysis data and the left is the result of one of the 100-member AGCM historical simulations. The cross mark indicates a flooded area. Extremely strong southerly moisture flowed into western Japan due to the zonal dipole of western cyclonic and eastern anticyclonic circulation patterns. The dipole pattern is well captured by the 60-km AGCM simulation. The lower two panels show the accumulated rainfall amount over the same period [mm], where the right was obtained from the JMA meso-reanalysis data (1-km horizontal resolution), and the left is the result of one of the 100-member NHRCM historical simulations. The 20-km NHRCM roughly captured the regional difference in rainfall amount depending on mountain ranges. The middle panel shows the accumulated rainfall output from the $60-\mathrm{km}$ AGCM. The rainy area was diagnosed in accordance with the synoptic convergence zones and regionality over the lands could not be distinguished.

incorporated both of these approaches to examine the effects of climate on Hurricane Harvey's extreme rainfall. Their storyline approach was similar to existing storyline EA based on RCMs, whereas their risk-based discussion on event frequency was based on large-ensemble simulations of relatively long-term future projections by a 100-km coupled GCM, where the poor resolution prevented accurate representation of event-specific convective systems. Based on this, large-ensemble simulations for risk-based EA should be conducted using a high-resolution RCM, although huge computational cost is a serious problem.

In this study, we conducted high-resolution large-ensemble simulations using RCM that were downscaled from large-ensemble GCM simulations to achieve risk-based EA of local heavy rainfall. Because extreme rainfall takes on different forms of atmospheric circulation in each location, each event was examined from the viewpoint of rainfall statistics simulated by the RCM and background large-scale circulation fields simulated by the GCM responsible for rainfall systems that differ according to each location. Global models specialise in capturing the background pathway of large-scale circulation changes associated with global warming. Hence, a large-ensemble set of GCM and RCM simulations is necessary to provide information on changing climate extremes with a reasonable understanding of background processes (Fig. 1). Here, we prepared a 100-member ensemble set of historical and non-warming simulations (hereafter HIST and NonW, respectively) with 100 pairs of Meteorological Research Institute atmospheric general circulation model 3.2 (MRI-AGCM3.2) with 60-km-mesh and non-hydrostatic regional climate model (NHRCM) with a 20-kmmesh for East Asia from 1981 to present, for a total of more than 3000 years for each ensemble (see 'Methods') ${ }^{26}$. The $20-\mathrm{km}$-mesh is not necessarily enough to represent fine rainfall systems, such as meso- $\gamma$ scale line-shaped precipitation systems, but is sufficient for representing meso- $\alpha$ or meso- $\beta$ scale systems such as fronts, tropical depressions and squall lines ${ }^{27}$. The difference between the $60-\mathrm{km}$ and $20-\mathrm{km}$ grid spacing is critical to the representation of
Japanese weather. The $60-\mathrm{km}$ resolution cannot distinguish the four main Japanese islands, whereas the $20-\mathrm{km}$ resolution can resolve those islands and can distinguish climate features in the windward and leeward side (Supplementary Fig. 1).

Based on this methodology, three episodes of extreme precipitation in Japan were attributed to anthropogenic climate change. The July 2018 episode (Case2018) was induced by abnormal moisture inflow toward a stationary rainband in the coastal regions of Japan's Inland Sea (Fig. 2a), and was characterised by its relatively long duration and extensive area of impact $^{28}$. The heaviest $72-\mathrm{h}$ accumulated rainfall was recorded at 123 observation sites from 28 June to 8 July, 2018 (reported by the Japan Meteorological Agency, JMA). The July 2017 episode (Case2017) was associated with abnormal moisture inflow toward the west side of the mountain range on the main island of Kyushu (Fig. 2b). The daily maximum rainfall exceeded $500 \mathrm{~mm}$ per day in the worst-hit area from 5 to 6 July (JMA). Both cases accompanied the active Baiu rainband. The ascending current and instability of the Baiu rainband were enhanced by the upper-level westerly jet and travelling synoptic waves, the mid-level advection of warm and moist air influenced by the South Asian thermal low, and low-level southerly moisture transport associated with an enhanced north Pacific subtropical high (NPSH) ${ }^{29}$. All of these circulation features were observed in Case2018 ${ }^{30}$. For Case2017, enhanced NPSH was notably observed. The July 1993 episode (Case1993) was caused by a series of TC landfalls on the east side of the Kyushu Island mountain range (Fig. 2c). Two TCs, following similar tracks, made landfall 2 days apart from each other. Daily maximum rainfall exceeded $300 \mathrm{~mm}$ per day at several observation sites (JMA).

\section{RESULTS}

Validation of model reproducibility

First, we confirmed whether these rainfall systems and responsible atmospheric circulations in each location are successfully classified 

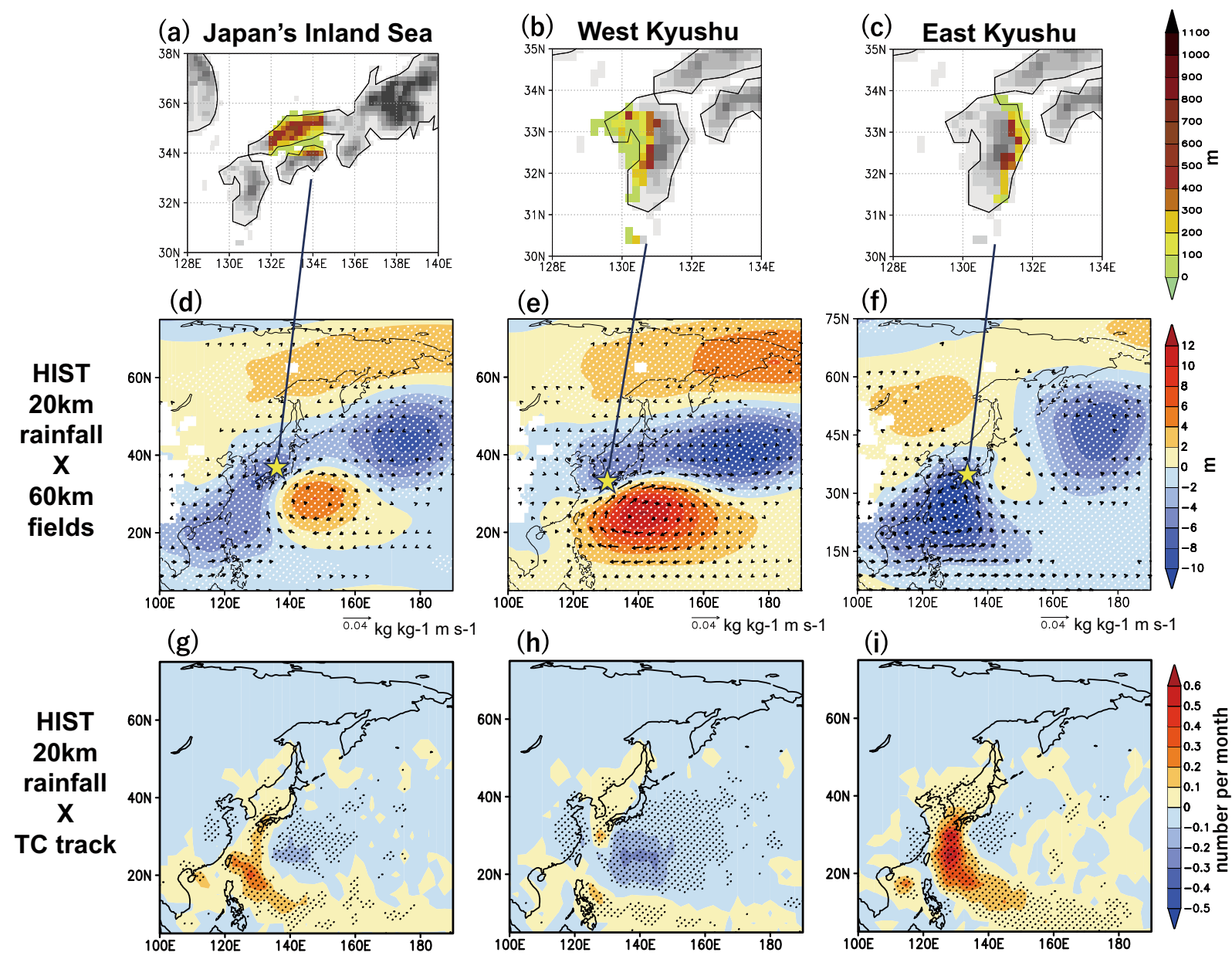

Fig. 2 Relationship between occurrence frequency of local heavy rainfall and background synoptic circulation. a-c Elevation maps [m]. Colour shading illustrates the analysis regions of Japan's Inland Sea, West Kyushu and East Kyushu, respectively. d-i Regression coefficients of $\mathrm{Z} 850[\mathrm{~m}]$ and column-integrated water vapour fluxes $\left[\mathrm{kg} \mathrm{kg}^{-1} \mathrm{~m} \mathrm{~s}^{-1}\right]$ (shading and vectors in upper panels), and TC density [accumulated number per month] (bottom panels) onto occurrence frequency indices of local heavy rainfall (the accumulated number of days with more than $100 \mathrm{~mm}$ per day over areas in (a), (b) and (c)) were synthesised from the HIST simulations of MRI-AGCM3.2 and NHRCM from 1981 to 2010. The Z850, water vapour fluxes and TC density were obtained from the MRI-AGCM3.2 outputs, whereas the local heavy rainfall was obtained from the NHRCM output. The white and black dots represent significant differences at the $95 \%$ confidence level, according to Student's $t$-test.

by our simulations. This was done by calculating regression coefficients between each local heavy precipitation frequency index calculated from NHRCM and large-scale circulations $(850 \mathrm{hPa}$ geopotential height, column moisture flux and TC density) from MRI-AGCM3.2 using 3000-year samples (100 ensemble members from 1981 to 2010). Figure 2e indicates that the heavy rainfall frequency on the west side of the Kyushu mountain range increases when the NPSH is active and southwesterly moisture flow around the NPSH converges in this region. The negative height anomalies around $40^{\circ} \mathrm{N}$ correspond to the enhanced Baiu rainband. In the upper troposphere, the features of synoptic waves travelling along the westerly jet are also significant (Supplementary Fig. 2). This indicates that the specific features of the enhanced Baiu rainband identified by Sampe and $\mathrm{Xie}^{29}$ are well-represented in our model simulations. TCs do not significantly affect heavy rainfall in this region, likely due to the active NPSH (Fig. 2h). The southwesterly moisture inflow is also present over eastern Kyushu, but it rarely causes heavy rainfall on the eastern side, likely due to the Kyushu mountain range being in a northsouth configuration which would blocks the moisture inflow. Instead, the major cause of the heavy rainfall is TCs which approach eastern Kyushu (Fig. 2i), suggesting that NPSH is not the key factor (Fig. 2f). This is also marginally observable when the same regression map was drawn using the site-observation and reanalysis data with less significance due to the smaller sample size (Supplementary Fig. 3), indicating the advantage of using large-ensemble data. In the relatively dry regions around Japan's Inland Sea (Fig. 2d, g), the situation is similar to TC-induced heavy rainfall in Fig. $2 f, i$, and the dipole of the western trough and the eastern ridge partly promotes southerly moisture flow, although both relationships are smaller (but statistically significant) than the other two types. This implies that the patterns in Fig. $2 \mathrm{~d}, \mathrm{~g}$ are the result of a combination of factors.

We also compared the leading modes of interannual variability in the circulation patterns over East Asia between the MRIAGCM3.2 ensemble simulations of HIST and the JRA55 reanalysis from 1981 to 2010, confirming that the leading Rossby wave patterns over East Asia are well-represented in the MRI-AGCM3.2 large-ensemble simulations (Supplementary Fig. 4). In addition to these meso- $\alpha$ to meso- $\beta$ scale rainfall systems, smaller-scale phenomena such as line-shaped precipitation systems and orographic precipitation induced by complex topography are often observed during heavy rainfall events in these regions. As mentioned above, the $20-\mathrm{km} \mathrm{NHRCM}$ is insufficient to resolve 


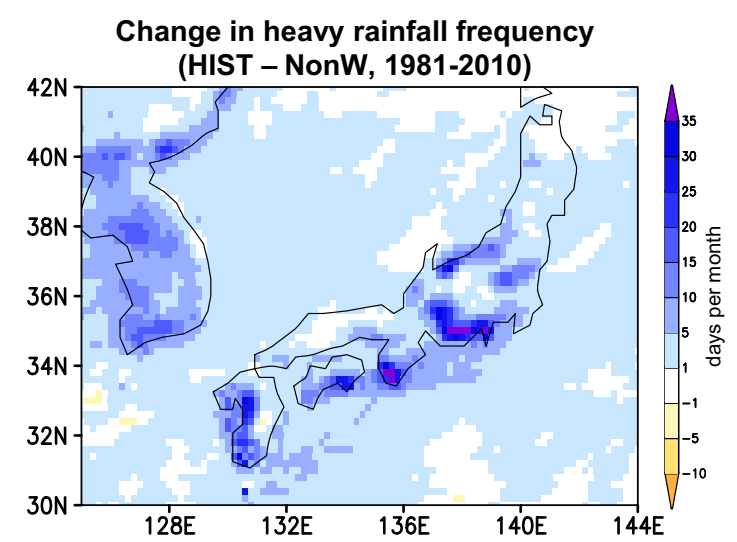

Fig. 3 Past changes in heavy rainfall frequency. Changes in heavy rainfall frequency (the number of days with more than $100 \mathrm{~mm}$ per day) in July between the HIST and NonW simulations from 1981 to 2010 . The heavy rainfall frequency was obtained from the RCM outputs.

these meso- $\gamma$ scale phenomena. Thus, in this study, we considered rainfall systems larger than meso- $\beta$ scale, which were the key contributors to triggering the extreme rainfall events of focus.

\section{Attribution of long-term trends in heavy rain frequency}

Figure 3 shows the difference in heavy rainfall frequency (the number of days with more than $100 \mathrm{~mm}$ per day) during the month of July from 1981 to 2010 between the HIST and NonW simulations. It was noted that the impact of global warming on the July 1981-2010 heavy rainfall frequency was strong on the western side of the mountain range because the moisture increase due to warming have directly enhanced the southwesterly moisture convergence ${ }^{18}$. However, the difference was relatively small in eastern Kyushu and the regions of Japan's Inland Sea. In the eastern Kyushu region, large uncertainty in simulated TCs prevented accurate detection of significant differences ${ }^{18}$. In the coastal regions of Japan's Inland Sea, heavy rainfall differences were difficult to attribute to climate warming due to various kind of atmospheric variabilities from year to year. Figure 3 implies that Case2018 (Japan's Inland Sea; various factors) and Case1993 (eastern Kyushu; TC-induced) extreme rainfall events are less likely to be attributed to anthropogenic climate change than Case2017 (western Kyushu; orographic moisture convergence).

\section{Risk-based event attribution}

Figure 4 compares Case2018-like, Case2017-like and Case1993-like event probabilities between the HIST and NonW simulations. Three-day accumulated rainfall was used for Case2018, and daily rainfall was used for Case2017 and Case1993. Because the simulated daily rainfall of $20 \mathrm{~km}-\mathrm{RCM}$ slightly underestimated the frequency of intense rainfall of more than $200 \mathrm{~mm}$ per day ${ }^{18}$, we used a 50-year return value of each 3000 sample (100 members from 1981 to 2010) of the HIST simulation as a threshold instead of observed values (see 'Methods'). Contrary to Fig. 3, Fig. 4 shows a significant increase in extreme rainfall frequency not only in Case2017-like events (western Kyushu) but also in Case2018-like events (Japan's Inland Sea) when we focused on each episode. Figure 4a (Case2018-like events) indicates that the threshold of 72-h rainfall was estimated to have 20.7-year return period under the realistic 2018 climatic conditions, but would have a 68.0-year return period under counterfactual conditions free of human-induced climate change. That is, the probability increased from $1.47 \%$ (with a confidence interval of $1.22-1.71 \%$ which are the 2th-98th percentiles of 5000 bootstrap random samples) to $4.82 \%(4.38-5.27 \%)$ due to human activity. In the same way, Fig. 4b (Case2017-like events) indicates that the return period (probability) of daily maximum rainfall changed from 53.5 years $(1.87 \%$ with a confidence interval of $1.61-2.12 \%)$ to 36.0 years $(2.78 \%$ with a confidence of $2.48-3.08 \%)$ due to global warming. Such an influence was not detectable in the TC-induced type events, as in Case1993 (Fig. 4c).

We analysed the background specific synoptic pressure patterns in Case2017 and Case2018. The observed and ensemble-mean circulation anomalies are shown in Fig. 5. Anomaly patterns from the reanalysis data and the ensemblemean simulation were partly dissimilar to each other because the anomaly by the JRA55 reanalysis (Fig. $5 \mathrm{a}, \mathrm{c}$ ) was only one sample including stochastic intrinsic variability, whereas the simulated anomaly (Fig. 5b, d) was the average of 100 members where stochastic intrinsic components were cancelled out. The signals obtained from the ensemble-mean values indicate that the background conditioning behind the event of focus is forced by boundary conditions prescribing MRI-AGCM3.2, such as sea surface temperature (SST). The anomalies for Case2017 (western Kyushu) (Fig. 5c, d) show patterns conditioned by the enhanced NPSH and southwesterly moisture flow, which indicates high heavy rainfall potential as shown by Sampe and $\mathrm{Xie}^{29}$. Similarly, the observed and ensemble-mean anomalies for Case2018 (Japan's Inland Sea) (Fig. 4a, b) show that the background field was conditioned by the zonal pressure dipole and the southerly moisture flow. This means that, if the 2018 episode was separated from the other events in the coastal region of Japan's Inland Sea, the conditions of Case2018 and Case2017 would be similar in that moisture convergence was the main driver of high heavy rainfall potential. This is why Case2018-like events were also attributable to anthropogenic global warming.

\section{DISCUSSION}

In general, EA results largely depend on background conditioning. Local rainfall changes depend on both background circulation (dynamic) and moisture (thermodynamic) changes. Increased water vapour is a common trend due to global warming, but the reasons for changes in dynamic components are still poorly understood and are thought to be region-dependent ${ }^{31}$. We used the pressure dipole indices to characterise the circulation features for Case2017 (see 'Methods'). Regarding background circulation changes, there is little difference between the HIST and NonW simulations (Fig. 4d), although the 2017 PDFs (both from the HIST (red solid line) and NonW (blue solid line) simulations) are completely separated from the PDF of long-term statistics (shadings). Generally, detection of circulation changes is difficult in the current warming stage because of the large natural variability within dynamical processes. Therefore, the existing EA approach experienced difficulty in detecting extreme rainfall changes. The significant findings of this study are that the ensemble simulations represented the 2017 orographic moisture convergence and 2018 stationary moisture advection well in the ensemble-mean fields as signals (Fig. 5b, d), and that the event probability (Fig. 4a, b) were conditioned on the dynamic situation leading to the event. Because of its moderate constraint on the moisture advection, the role of moisture increase due to global warming was noted in both Case2017 and Case2018. The TCinduced extreme rainfall (Case1993), however, was not attributable to anthropogenic climate change because the occurrence of heavy rainfall depended more on the TC approach rather than on the moisture increase due to global warming. Historical changes in TC density are not detectable at this stage because of large natural variability and problems in reproducibility of TCs by the GCM outside the boundary of the RCM. Furthermore, recent studies have shown that aerosol cooling reduces TC potential intensity 


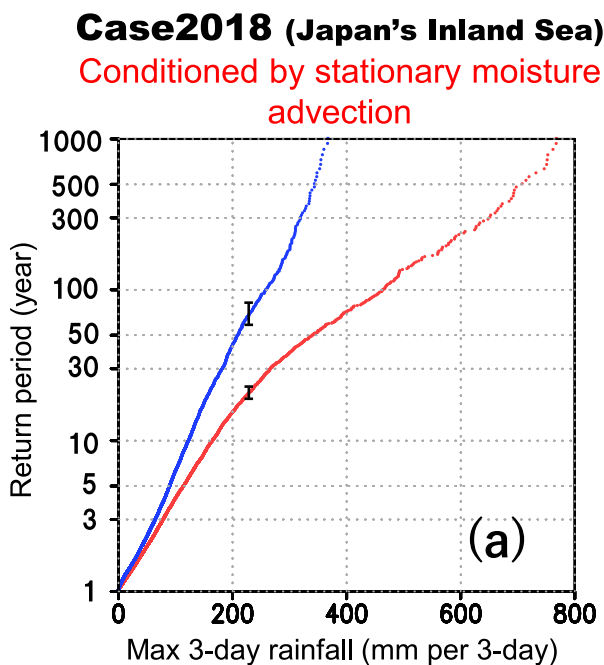

Case1993 (East Kyushu)

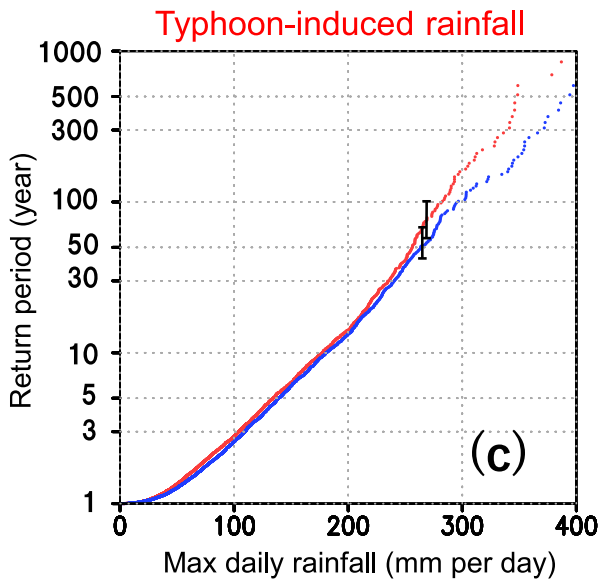

Case2017 (West Kyushu)

Orographic moisture

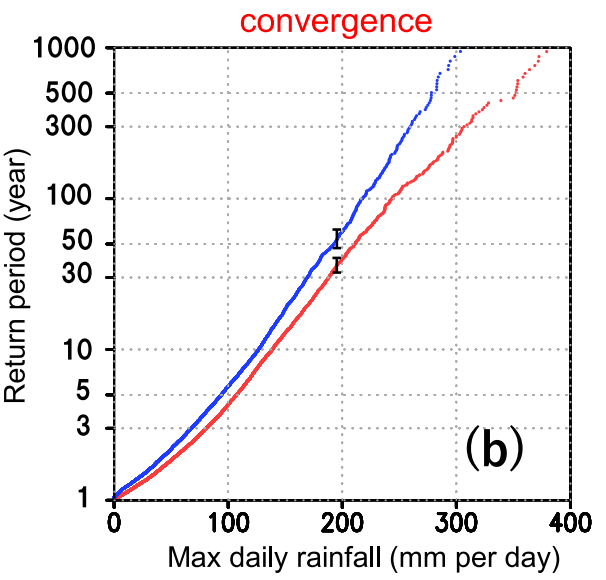

Case 2017 (West Kyushu)

Synoptic circulation index

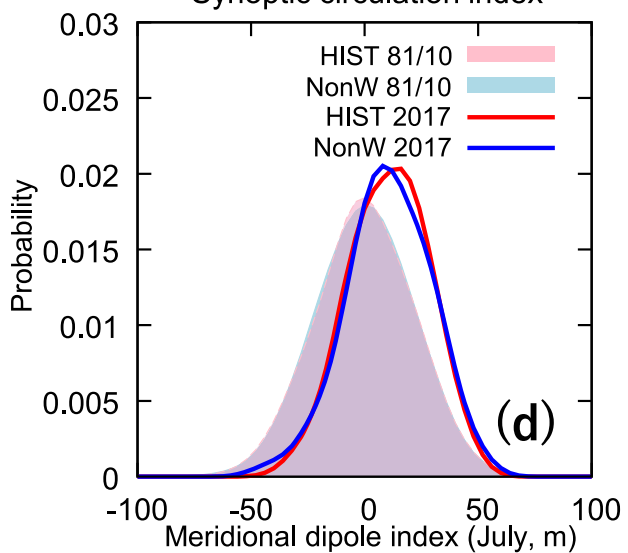

Fig. 4 Change in return periods of heavy rainfall indices. a-c Return period curves of maximum 3-day accumulated rainfall [mm per 3 days] from 28 June to 8 July (a; Case2018), daily maximum rainfall [mm per day] from 1 July to 10 July (b; Case2017), and daily maximum rainfall from 1 July to 31 July (c; Case1993) synthesised from all precipitation simulations in the HIST and NonW climates. d Probability density functions (PDF) of zonal dipole indices [m] for Case2017. Each panel shows two curves of the HIST (red) and NonW (blue) large-ensemble simulations. In (a-c), bars represent 2-98\% confidence intervals based on the Monte Carlo bootstrap resampling method at each threshold (see 'Methods'). In (d), the shadings are PDFs based on 30-year statistics from 1981 to 2010. The values in (a-c) were obtained from the NHRCM outputs, whereas the index in (d) was calculated from the MRI-AGCM3.2 outputs.

and counteracts an increasing effect due to greenhouse gas warming, which can be a cause of the uncertainty of a TC simulation ${ }^{32,33}$.

Our particular interest is that a comparison of the long-term probability (e.g. 1981-2010 as in Fig. 3) between the HIST and NonW ensembles reveals an almost undetectable difference in the coastal region of Japan's Inland Sea. This is thought to be due to the long-term runs, which include various types of rainfall systems with large uncertainties due to natural variability. However, by the model background conditioning of the 2018-like specific pressure patterns, the dynamic circulation uncertainty decreased, and we detected a change in event probability and attribute it to anthropogenic global warming.

We classified the regional rainfall processes according to the large-scale circulation types and connected each process change to anthropogenic global warming by analysing regional model outputs concurrently with parent global model outputs. This study is an attempt to extend the large-ensemble pairs of regional and global model simulations for the purposes of risk-based EA. If the large-ensemble outputs represent dynamic background conditions leading to a target event in their ensemble-mean field, the risk of heavy rainfall events can be confidently attributed to human activity $^{5}$. Regarding Case2018, we also conducted a conventional storyline EA using NHRCM with a $5-\mathrm{km}$ horizontal resolution ${ }^{19}$. By combining the storyline EA with the risk-based EA, we made more comprehensive assessments of the effect of anthropogenic climate change on extreme rainfall events. This study offers a new direction in the field of high-resolution RCM studies.

\section{METHODS}

The observational dataset

The station dataset for daily precipitation was obtained from the Automated Meteorological Data Acquisition System (AMeDAS) maintained by the Japan Meteorological Agency. Approximately 1300 stations at 17$\mathrm{km}$ intervals were available. The analysis period from 1981 to the present day used in this study was determined by the availability of AMeDAS stations, which began surface observations around 1980. The observed anomaly was defined with a reference period between 1981 and 2010. For geopotential heights and column-accumulated water vapour fluxes, we used the 55-year Japanese Reanalysis (JRA55) dataset (ref. ${ }^{34}$ ). Typhoon best track data were obtained from the Regional Specialized Meteorological Centres Tokyo - Typhoon Centre. 


\section{Case2018 (Japan's Inland Sea)}

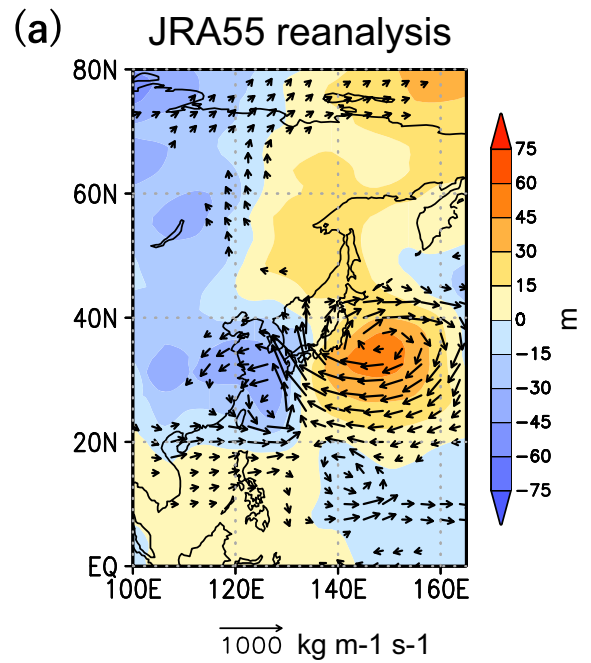

(b) HIST2018 100-member mean

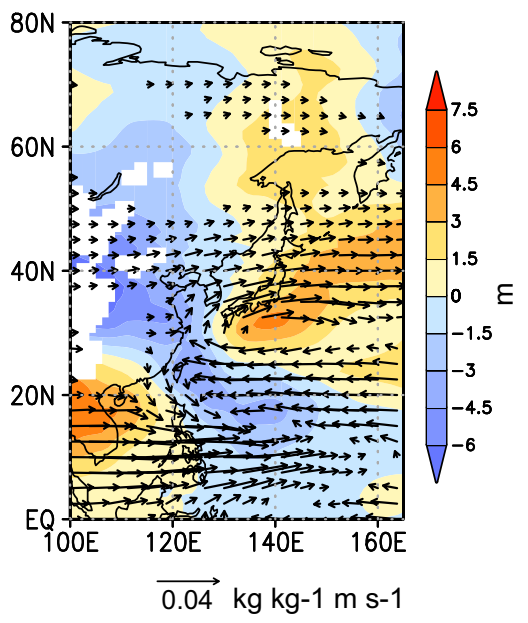

Case2017 (West Kyushu)

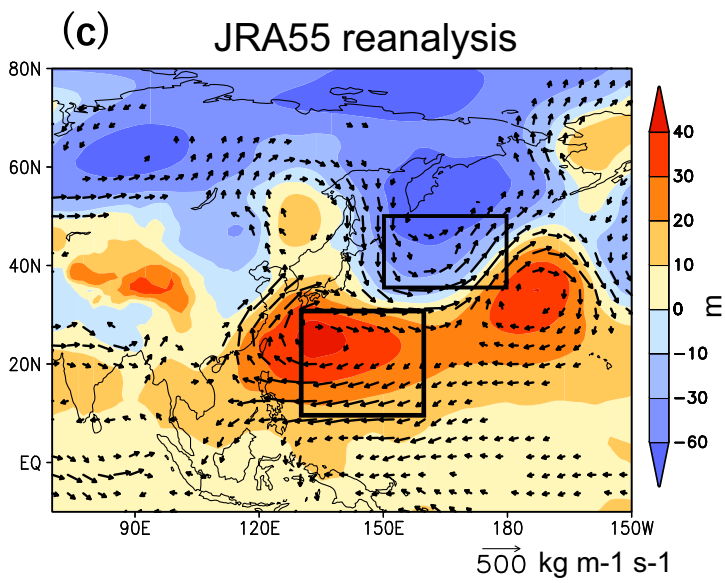

(d) HIST2017 100-member mean

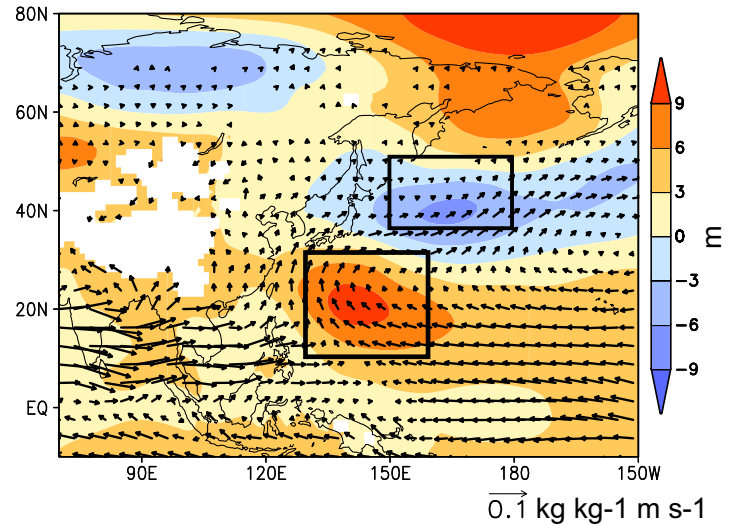

Fig. 5 Synoptic circulation patterns in Case2018 and Case2017. Anomalies from the JRA55 reanalysis (left) and ensemble-mean anomalies from the MRI-AGCM3.2 HIST simulations (right) of Z850 (m, shading) and column-integrated water vapour fluxes (kg m ${ }^{-1} \mathrm{~s}^{-1}$ for JRA55, kg $\mathrm{kg}^{-1} \mathrm{~m} \mathrm{~s}^{-1}$ for HIST, vectors) for Case2018 (upper) and Case2017 (lower).

Large-ensemble simulations

Our large-ensemble pairs of GCM and RCM simulations were part of the Database for Policy Decision-Making for Future Climate Change (d4PDF) (ref. ${ }^{26}$ ). The global climate simulations were conducted using MRIAGCM3.2 with $\sim 60-\mathrm{km}$ grid spacings (ref. ${ }^{35}$ ). We conducted largeensemble regional climate simulations that were downscaled from the large ensemble of MRI-AGCM3.2 using NHRCM with 20-km-grid spacing $\left(\right.$ ref. ${ }^{36}$ ). The regional climate simulation covered the East Asian region. The d4PDF's official historical/non-warming datasets covered the period from 1951 to 2010, with calculations extended to the present month as a quasireal-time product.

The HIST simulations were forced by the historical SST and sea ice thickness/concentration based on COBE-SST2 (ref. ${ }^{37}$ ) and historical anthropogenic and natural forcing agents such as greenhouse gases and solar irradiance (Representative Concentration Pathway 4.5 emission scenario after 2006) with a 100-member ensemble with different initial conditions and SST perturbations from 1951 to the present. The NonW simulations were forced by historical natural forcing agents and counterfactual "natural" SST and sea ice estimated by removing the warming trends observed in the 20th century. The greenhouse gas concentrations, anthropogenic aerosols and volcanic sulfate aerosols were fixed at 1850 values in the NonW simulation (for more details, refer to ref. ${ }^{38}$ ).

\section{Precipitation and circulation indices}

The coastal region of Japan's Inland Sea, western Kyushu and eastern Kyushu were defined as coloured grids in Fig. 2a-c, respectively. Depending on the timescale of each event, 72 -hour accumulated rainfall (the maximum on each grid during 28 June to 8 July) was used for Case2018, and daily maximum rainfall was used for Case2017 (the maximum during 1-10 July) and Case1993 (the maximum during 1-31 July). Because the rainfall simulated by the 20-km-mesh NHRCM underestimated that which was recorded at the observation site $\left(\right.$ ref. $^{18}$ ), we used probability precipitation with a 50-year return period calculated from the 30-year (1981-2010) d4PDF HIST simulation as a threshold. We estimated the sampling uncertainty in Fig. 4 using the Monte Carlo bootstrap sampling method.

The background circulation index for Case2017 was defined as the difference between the area-averaged $850 \mathrm{hPa}$ geopotential height over the region $\left[10^{\circ}-30^{\circ} \mathrm{N}, 130^{\circ} \mathrm{E}-160^{\circ} \mathrm{E}\right]$ and the region $\left[35^{\circ}-50^{\circ} \mathrm{N}, 150^{\circ} \mathrm{E}-180^{\circ} \mathrm{E}\right]$, which represents a meridional dipole pressure pattern inducing southwesterly moisture flow. The index was calculated every July.

\section{DATA AVAILABILITY}

The large-ensemble d4PDF simulation data used for drawing Figs. 2 and 3 are available at http://search.diasjp.net/en/dataset/d4PDF_GCM (AGCM outputs) and http://search.diasjp.net/en/dataset/d4PDF_RCM (NHRCM outputs) for the period from 1981 to 2010. The d4PDF large-ensemble data (local rainfall data during rainy season 
in 1993, 2017 and 2018) used for drawing Figs. 1, 4 and 5 are available for research purpose at https://climate.mri-jma.go.jp/pub/archives/Imada-et-al_d4PDF-extend. The JRA55 reanalysis is available at https://jra.kishou.go.jp/JRA-55/index_en. html\#download.

\section{CODE AVAILABILITY}

This study does not use any unreported custom computer code or mathematical algorithm that is deemed central to the conclusions.

Received: 14 January 2020; Accepted: 28 August 2020;

Published online: 23 September 2020

\section{REFERENCES}

1. Hartmann, D. L. et al. In Climate Change 2013: The Physical Science Basis. Contribution of Working Group I to the Fifth Assessment Report of the Intergovernmental Panel on Climate Change (eds Stocker, T. F. et al.) (Cambridge University Press, Cambridge and New York, NY, 2013).

2. Stott, P. A. Attribution of extreme weather and climate-related events. Wiley Interdiscip. Rev.: Clim. Change 7, 23-41 (2016).

3. Otto, F. The art of attribution. Nat. Clim. Change 6, 342-343 (2016).

4. EDITORIAL. Pinning extreme weather on climate change is now routine and reliable science. Nature 560, 5 (2018).

5. Shepherd, T. G. A common framework for approaches to extreme event attribution. Curr. Clim. Change Rep. 2, 28-38 (2016).

6. Imada, Y. et al. The contribution of anthropogenic forcing to the Japanese heat waves of 2013. Bull. Am. Meteorol. Soc. 95, S52-S54 (2014).

7. Imada, Y. et al. The July 2018 high temperature event in Japan could not have happened without human-induced global warming. SOLA 15A, 8-12 (2019).

8. Pardeep, P. T. et al. Anthropogenic greenhouse gas contribution to flood risk in England and Wales in autumn 2000. Nature 470, 382-386 (2011).

9. Imada, Y. et al. Contribution of atmospheric circulation change to the 2012 heavy rainfall in southwestern Japan. Bull. Am. Meteorol. Soc. 94, S52-S54 (2013).

10. King, A. D. et al. Limited evidence of anthropogenic influence on the 2011-12 extreme rainfall over Southeast Australia. Bull. Am. Meteorol. Soc. 94, S55-S58 (2013).

11. Oldenborgh, G. J. van et al. Rapid attribution of the May/June 2016 floodinducing precipitation in France and Germany to climate change. Hydrol. Earth Syst. Sci. Discuss. https://doi.org/10.5194/hess-2016-308 (2016).

12. Schaller, N. et al. Human influence on climate in the 2014 southern England winter floods and their impacts. Nat. Clim. Change 6, 627-634 (2016).

13. Burke, C., Stott, P., Sun, Y. \& Ciavarella, A. Attribution of extreme rainfall in Southeast China during May 2015. Bull. Am. Meteorol. Soc. 97, S92-S96 (2016).

14. Oldenborgh, G. Jvan et al. Attribution of extreme rainfall from Hurricane Harvey, August 2017. Environ. Res. Lett. 12, 124009 (2017).

15. Otto, F. E. L. et al. Climate change increases the probability of heavy rains in Northern England/Southern Scotland like those of storm Desmond-a real-time event attribution revisited. Environ. Res. Lett. 13, 024006 (2018).

16. Hoerling, M. et al. Northeast Colorado extreme rains interpreted in a climate change context. Bull. Am. Meteorol. Soc. 95, S15-S18 (2014).

17. Lenderink, G., Barbero, R., Loriaux, J. M. \& Fowler, H. J. Super Clausius-Clapeyron scaling of extreme hourly convective precipitation and its relation to large-scale atmospheric conditions. J. Clim. 30, 6037-6052 (2017).

18. Kawase et al. Contribution of historical global warming to local-scale heavy precipitation in western Japan estimated by large ensemble high-resolution simulations. J. Geophys. Res. Atmos. 124, 6093-6103 (2019).

19. Kawase, $\mathrm{H}$. et al. The heavy rain event of July 2018 in Japan enhanced by historical warming. Bull. Am. Meteorol. Soc. 101, 109-114 (2020).

20. Takayabu, l. et al. Climate change effects on the worst-case storm surge: a case study of Typhoon Haiyan. Environ. Res. Lett. 10, 064011 (2015).

21. Wehner, M. F., Reed, K. A. \& Zarzycki, C. M. In Hurricanes and Climate Change (eds Collins, J. \& Walsh, K.) (Springer, Cham, 2017).

22. Wehner, M. F., Zarzycki, C. \& Patricola, C. In Hurricane Risk (eds Collins, J. \& Walsh, K.) Vol. 1. (Springer, Cham, 2019).

23. Patricola, C. M. \& Wehner, M. F. Anthropogenic influences on major tropical cyclone events. Nature 563, 339-346 (2018).

24. Reed, K. A., Stansfield, A. M., Wehner, M. F. \& Zarzycki, C. M. Forecasted attribution of the human influence on Hurricane Florence. Sci. Adv. 6, eaaw9253 (2020).

25. Wang, S.-Y. S., Zhao, L., Yoon, J.-H., Klotzbach, P. \& Gillies, R. R. Quantitative attribution of climate effects on Hurricane Harvey's extreme rainfall in Texas. Environ. Res. Lett. 13, 054014 (2018)
26. Mizuta, R. et al. Over 5000 years of ensemble future climate simulations by $60 \mathrm{~km}$ global and $20 \mathrm{~km}$ regional atmospheric models. Bull. Am. Meteorol. Soc. 98, 1383-1398 (2017).

27. Orlanski, I. A rational subdivision of scales for atmospheric processes. Bull. Am Meteorol. Soc. 56, 527-530 (1975).

28. Simpo, A. et al. Primary factors behind the heavy rain event of July 2018 and the subsequent heat wave in Japan. SOLA 15A, 13-18 (2019).

29. Sampe, T. \& Xie, S.-P. Large-scale dynamics of the Meiyu-Baiu rainband: environmental forcing by the westerly jet. J. Clim. 23, 113-134 (2010).

30. Wang, S. S.-Y. et al. Consecutive extreme flooding and heat wave in Japan: are they becoming a norm? Atmos. Sci. Lett. 20, e933 (2019).

31. Pfahl, S., O'Gorman, P. A. \& Fischer, E. M. Understanding the regional pattern of projected future changes in extreme precipitation. Nat. Clim. Change 7, 423-427 (2017)

32. Reale, O., Lau, K. M., da Silva, A. \& Matsui, T. Impact of assimilated and interactive aerosol on tropical cyclogenesis. Geophys. Res. Lett. 41, 3282-3288 (2014).

33. Sobel, A. H., Camargo, S. J. \& Previdi, M. Aerosol versus greenhouse gas effects on tropical cyclone potential intensity and the hydrologic cycle. J. Clim. 32, 5511-5527 (2019).

34. Kobayashi, S. et al. The JRA-55 reanalysis: general specifications and basic characteristics. J. Meteor. Soc. Jpn. 93, 5-48 (2015).

35. Mizuta, R. et al. Climate simulations using MRI-AGCM3.2 with 20-km grid. J. Meteor. Soc. Jpn. 90A, 233-258 (2012).

36. Sasaki, H., Kurihara, K., Takayabu, I. \& Uchiyama, T. Preliminary experiments of reproducing the present climate using the non-hydrostatic regional climate model. SOLA 4, 25-28 (2008).

37. Hirahara, S., Ishii, M. \& Fukuda, Y. Centennial-scale sea surface temperature analysis and its uncertainty. J. Clim. 27, 57-75 (2014)

38. Shiogama, $\mathrm{H}$. et al. Attributing historical changes in probabilities of recordbreaking daily temperature and precipitation extreme events. SOLA 12, 225-231 (2016).

\section{ACKNOWLEDGEMENTS}

We are grateful to M. Mori and C. Takahashi for their cooperation. This work was supported by the Integrated Research Program for Advancing Climate Models (TOUGOU) Grant Number JPMXD0717935457 and JPMXD0717935561 from the Ministry of Education, Culture, Sports, Science and Technology (MEXT), Japan. This study utilized the d4PDF, which was produced using the Earth Simulator as "Strategic Project with Special Support" of JAMSTEC in cooperation with the Program for Risk Information on Climate Change (SOUSEI), TOUGOU, the Social Implementation Program on Climate Change Adaptation Technology (SI-CAT), which all were sponsored by the MEXT, Japan. This study was partly supported by Japan Science and Technology Agency (JST) and Japan Society for the Promotion of Science (JSPS) Grants-in-Aid for Scientific Research (KAKENHI) Grant Number $18 \mathrm{~K} 03749$

\section{AUTHOR CONTRIBUTIONS}

Y.I. led the research, performed the experiments and wrote the paper. H.K. led the research and performed the experiments. M.A. performed the experiments. M.W., H.S. and I.T. contributed to improve the analysis. All the authors discussed the results and commented on the paper.

\section{COMPETING INTERESTS}

The authors declare no competing interests.

\section{ADDITIONAL INFORMATION}

Supplementary information is available for this paper at https://doi.org/10.1038/ s41612-020-00141-y.

Correspondence and requests for materials should be addressed to Y.I.

Reprints and permission information is available at http://www.nature.com/ reprints

Publisher's note Springer Nature remains neutral with regard to jurisdictional claims in published maps and institutional affiliations. 
Open Access This article is licensed under a Creative Commons Attribution 4.0 International License, which permits use, sharing, adaptation, distribution and reproduction in any medium or format, as long as you give appropriate credit to the original author(s) and the source, provide a link to the Creative Commons license, and indicate if changes were made. The images or other third party material in this article are included in the article's Creative Commons license, unless indicated otherwise in a credit line to the material. If material is not included in the article's Creative Commons license and your intended use is not permitted by statutory regulation or exceeds the permitted use, you will need to obtain permission directly from the copyright holder. To view a copy of this license, visit http://creativecommons. org/licenses/by/4.0/.

(c) The Author(s) 2020 